\title{
Case Report \\ Rare Case of Large Bowel Injury due to Direct Blunt Trauma to a Preexisting Femoral Hernia
}

\author{
C. Tinner, M. Odermatt, and P. Villiger \\ Department of Abdominal Surgery, General Hospital Chur, 7000 Chur, Switzerland \\ Correspondence should be addressed to P. Villiger; peter.villiger@ksgr.ch
}

Received 14 June 2017; Accepted 9 August 2017; Published 25 October 2017

Academic Editor: Boris Kirshtein

Copyright (c) 2017 C. Tinner et al. This is an open access article distributed under the Creative Commons Attribution License, which permits unrestricted use, distribution, and reproduction in any medium, provided the original work is properly cited.

\begin{abstract}
We report a case of an 85-year-old man with a known asymptomatic left femoral hernia who was admitted to the emergency ward a few hours after falling from a bicycle and suffering from blunt trauma of the handlebar to the left inguinal region. The clinical findings and a computed tomography (CT) scan detecting free air in the femoral hernia sac suggested bowel perforation. Emergency laparotomy 6 hours after the incident confirmed a tear of the sigmoid colon accompanied by free blood and faeces in the left inguinal region of the abdomen. A segmental sigmoid resection and a primary end-to-end colorectal anastomosis were performed. The postoperative course was complicated by delayed oral feeding, a local infection, and a partial left testicle necrosis that led to secondary resection. The patient was discharged after 32 days of in-hospital care. Three months post trauma, we recorded a restitutio ad integrum. The case exemplifies that blunt trauma to preexisting femoral hernias may cause potentially lethal bowel perforation and that the time interval between time of injury and surgical treatment may be a prognostic factor. CT scans seem most suitable for ruling out bowel perforation. The scarce literature for blunt trauma to hernias is reviewed.
\end{abstract}

\section{Introduction}

Groin hernias are common, with an estimated prevalence of between 5 and 10 percent [1]. Although femoral hernias account for less than 10 percent of groin hernias, they occur more often than inguinal hernias associated with complications like incarceration and strangulation [2]. Femoral hernias are frequently found in elderly women, whereas inguinal hernias are more common in men [3]. On clinical examination, a groin hernia is easily detected, but diagnosis of a femoral hernia is more difficult and is more often confirmed during surgery. Symptomatic hernias are commonly treated surgically. However, considering that severe complications such as incarceration are uncommon, not all patients with asymptomatic hernias profit equally from surgical treatment. For patients with a high operative risk, conservative treatment may be a viable alternative. Guidelines for optimal surgical treatment have been published by the European Hernia Society [4, 5]. As femoral hernias are more prone to complications like incarceration, there is a general consensus that surgical repair should be the standard of care at an early stage [2]. Many patients with asymptomatic femoral hernias are unaware of their potential risks and do not seek medical advice. Therefore, femoral hernias are eventually diagnosed when becoming symptomatic and often require emergent admission and treatment. Very unusual, though potentially fatal, is another complication of untreated hernias, namely, the traumatic rupture of bowel trapped in a hernia sac. Only a few cases of traumatic bowel injuries associated with inguinal hernias are described in the literature. This is to our knowledge the first case report of a large bowel perforation due to a trauma to femoral hernia.

\section{Case Presentation}

An 85-year-old patient with a medical history of appendectomy, prostatic hyperplasia, and a known but untreated asymptomatic groin hernia had a bicycle accident with a blunt handlebar injury to his left inguinal area. Later on, he 


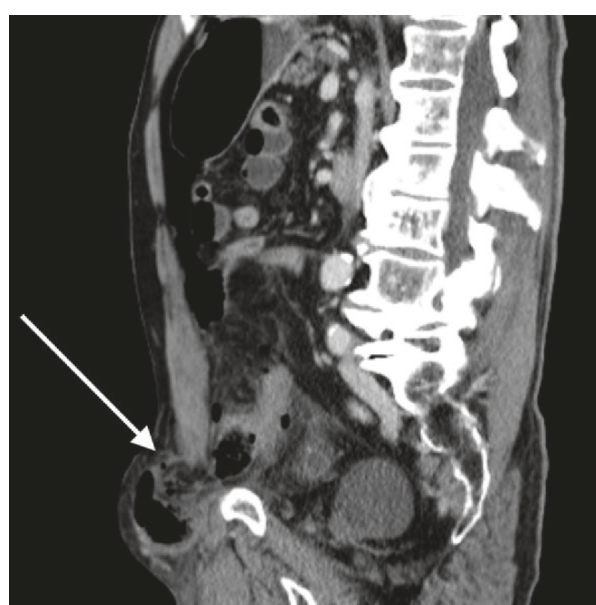

(a)

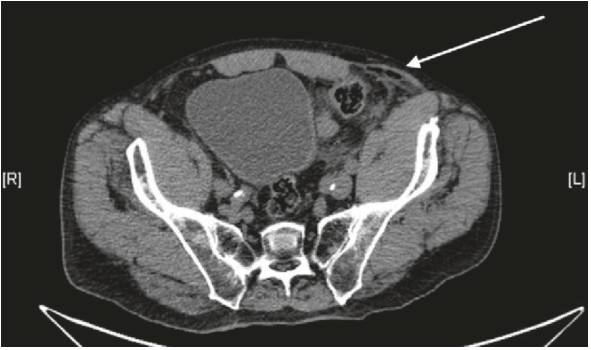

(b)

Figure 1: Femoral hernia with free air in preoperative CT: (a) sagittal and (b) axial.

TABLE 1: Literature overview of bowel perforations due to blunt trauma.

\begin{tabular}{|c|c|c|c|}
\hline Year, journal & Authors & Title & Treatment; outcome \\
\hline $\begin{array}{l}\text { 2014, Case Reports in } \\
\text { Emergency Medicine [6] }\end{array}$ & $\begin{array}{l}\text { Moustafa } \\
\text { et al. }\end{array}$ & $\begin{array}{l}\text { Diagnosis of an inguinal hernia after a blunt } \\
\text { inguinal trauma with an intestinal perforation }\end{array}$ & $\begin{array}{l}\text { Laparotomy, resection; discharge } \\
\text { on day } 10 \\
\end{array}$ \\
\hline 2012, Hernia [7] & Shahin et al. & $\begin{array}{c}\text { Small bowel perforation due to blunt } \\
\text { trauma to an } \\
\text { inguinal hernia: a case report and literature } \\
\text { review }\end{array}$ & $\begin{array}{l}\text { Minilaparotomy, suturing of } \\
\text { perforation, uneventful; discharge } \\
\text { after a few days }\end{array}$ \\
\hline 2011, Hernia [8] & $\begin{array}{l}\text { Westwood } \\
\text { and Milsom }\end{array}$ & $\begin{array}{l}\text { Colonic perforation following blunt trauma } \\
\text { to an inguinal hernia }\end{array}$ & $\begin{array}{l}\text { Laparoscopy, primary closure, } \\
\text { uneventful; discharge on day } 5\end{array}$ \\
\hline 2009, Hernia [9] & $\begin{array}{l}\text { Neuhaus } \\
\text { et al. }\end{array}$ & $\begin{array}{l}\text { Intestinal perforation following a blunt } \\
\text { abdominal } \\
\text { trauma in patients with pre-existing inguinal } \\
\text { hernia }\end{array}$ & $\begin{array}{l}3 \text { cases, laparotomy, } 2 \mathrm{x} \text { uneventful, } \\
1 \mathrm{x} \text { ileus, and incisional hernia }\end{array}$ \\
\hline 2009, Hernia [10] & $\begin{array}{l}\text { Ersoz } \\
\text { et al. }\end{array}$ & $\begin{array}{l}\text { Isolated terminal ileum perforation after a kick } \\
\text { blow to an inguinal hernia }\end{array}$ & $\begin{array}{l}\text { Direct suturing of perforation, } \\
\text { postoperatively uneventful; } \\
\text { discharge on day } 7\end{array}$ \\
\hline 2003, Hernia [11] & $\begin{array}{l}\text { Oncel } \\
\text { et al. }\end{array}$ & $\begin{array}{l}\text { Small bowel perforation due to blunt trauma } \\
\text { directly to the inguinal region: a case report }\end{array}$ & $\begin{array}{c}\text { Laparotomy, resection and anastomosis, } \\
\text { uneventful; discharge on day } 5 \\
\end{array}$ \\
\hline $\begin{array}{l}\text { 2000, American Journal } \\
\text { of Roentgenology [12] }\end{array}$ & $\begin{array}{l}\text { Uppot } \\
\text { et al. }\end{array}$ & $\begin{array}{c}\text { Intestinal perforation from blunt trauma to an } \\
\text { inguinal hernia }\end{array}$ & Laparotomy, colon resection \\
\hline 2000, Praxis [13] & $\begin{array}{l}\text { Nussbaumer } \\
\text { et al. }\end{array}$ & $\begin{array}{l}\text { Traumatic perforation of the small } \\
\text { intestine-a } \\
\text { rare complication of inguinal hernia }\end{array}$ & $\begin{array}{l}\text { Laparoscopy, direct suturing } \\
\text { of perforation }\end{array}$ \\
\hline
\end{tabular}

complained of pain in the left groin, whereupon his family brought him to the emergency department. He was alert and fully oriented. The abdominal examination revealed diffuse pain, a tense abdomen, and absent bowel sounds. In the left inguinal area, a tennis ball-sized hernia with purplish blue skin discoloration was still visible. Palpation tenderness of the hernia and the lower abdomen was present. The rest of the physical examination was inconspicuous. Laboratory tests revealed no abnormalities (C-reactive protein (CRP) $<1 \mathrm{mg} / \mathrm{l}$, white blood cell count $\left.9.4 \times 10^{9} / \mathrm{l}\right)$. A computed tomography (CT) scan detected free air in the femoral hernia sac and abdomen, suggesting bowel perforation (Figure 1).
The clinical presentation and the CT findings were indicative for laparotomy. Six hours post trauma, emergency laparotomy revealed a circumferential tear of the sigmoid colon accompanied with intra-abdominal perforation. The left inguinal fossa was contaminated with blood and faeces. The subphrenic site and the space between the bowel loops were free of neither faeces nor purulent fluid. A segmental sigmoid resection of $22 \mathrm{~cm}$ and a primary end-to-end colorectal anastomosis were performed. Optimal conditions with vital and uncontaminated bowel segments with excellent arterial perfusion justified omitting a diverting stoma. Following extensive lavage, the abdomen was closed leaving 
a drain. The postoperative course was complicated by delayed oral feeding and a local infection. Ten days after emergency laparotomy, the local conditions needed a surgical revision. The findings included a well-healed anastomosis as well as a partially necrotic left testicle, which had to be removed in an additional inguinal approach. The skin wound healed by secondary intention. With subsequent parenteral nutrition and simultaneous oral feeding, the patient was discharged 32 days after the accident and recovered fully until follow-up three months later.

\section{Discussion}

This case demonstrates that a simple hernia can be complicated by an uncommon and potentially dangerous trauma. In the English literature, we found only few reports on bowel perforation due to blunt trauma in the presence of inguinal hernias (Table 1). High pressure in the hernia sac combined with shearing injury of an irreducible hernia by direct blunt trauma may be causative. Reynolds described in 1995 how incoming and outgoing bowel loops are compressed on direct trauma to an inguinal hernia [14]. In an experimental setup, a pressure of 150-260 mmHg was sufficient to rupture a closed intestinal loop segment. A sudden blunt impact by, for example, an elbow to a gas-filled pouch could generate pressure peaks greater than $300 \mathrm{mmHg}$ [14]. In the present case, the sudden external pressure applied to the sealed loop in the hernia by falling onto the handlebar must have generated sufficient intraluminal pressure to cause perforation. Femoral hernias may be even more prone to such complications than inguinal hernias, as femoral hernias tend to be immobilized in the hernia sac, and they may also less easily slide back than inguinal hernias.

The outcome after surgery for colonic perforation is associated with high morbidity and mortality [15]. The most important determinant for the outcome is time to surgery [16]. Faria et al. analysed the American Society of Anaesthesiologists (ASA) classification, New Injury Severity Score (NISS), and the presence of colonic lesions and identified them as independent prognostic factors for postoperative morbidity. In case of severe faecal peritonitis, colostomy may be considered [17]. Robles-Castillo et al. compared primary closure to colostomy for treatment of traumatic colon injury and concluded that it should be case specific [18]. Chol and Lim showed that laparoscopy is a safe, feasible, and effective procedure for the evaluation and treatment of haemodynamically stable patients with abdominal trauma [19]. However, in cardiopulmonary unstable patients with high probability for intra-abdominal injuries, primary laparotomy is mandatory. Once decided, surgical intervention should occur without delay, as it is crucial to shorten the time for intraperitoneal contamination and associated morbidity.

\section{Conclusion}

Preexisting inguinal or femoral hernias render the bowel more vulnerable to direct physical trauma potentially resulting in a life-threatening bowel perforation. This is one reason more to consider surgical repair in fit patients. In case of groin trauma, even if unspectacular, and subsequent signs of local peritonitis, the possibility of bowel perforation due to a preexisting hernia should be thought of and adequate diagnosis by CT scan should follow.

\section{Disclosure}

This manuscript was presented as an abstract on ECTESAbstracts 2017 and presented as a poster on "Digital Poster Presentation SGC-SSC Congress 2017.”

\section{Conflicts of Interest}

The authors declare that they have no conflicts of interest.

\section{References}

[1] N. Dabbas, K. Adams, K. Pearson, and G. T. Royle, "Frequency of abdominal wall hernias: is classical teaching out of date?," JRSM Short Reports, vol. 2, no. 1, p. 5, 2011.

[2] N. C. Gallegos, J. Dawson, M. Jarvis, and M. Hobsley, "Risk of strangulation in groin hernias," British Journal of Surgery, vol. 78, no. 10, pp. 1171-1173, 1991.

[3] C. E. Ruhl and J. E. Everhart, "Risk factors for inguinal hernia among adults in the US population," American Journal of Epidemiology, vol. 165, no. 10, pp. 1154-1161, 2007.

[4] G. Weber, "Principles of the management of adult inguinal hernia-recommendations by the European Hernia Society," Magyar Sebészet, vol. 63, no. 5, pp. 287-296, 2010.

[5] M. Miserez, E. Peeters, T. Aufenacker et al., "Update with level 1 studies of the European Hernia Society guidelines on the treatment of inguinal hernia in adult patients," Hernia, vol. 18, no. 2, pp. 151-163, 2014.

[6] F. Moustafa, J. Avouac, M. A. Vaz, and J. Schmidt, "Diagnosis of an inguinal hernia after a blunt inguinal trauma with an intestinal perforation," Case Reports in Emergency Medicine, vol. 2014, Article ID 653847, 3 pages, 2014.

[7] Y. Shahin, G. Sahota, A. Hotouras, A. Agarwal, and G. Tierney, "Small bowel perforation due to blunt trauma to an inguinal hernia: a case report and literature review," Hernia, vol. 16, no. 3, pp. 349-350, 2012.

[8] D. A. Westwood and P. B. Milsom, "Colonic perforation following blunt trauma to an inguinal hernia," Hernia, vol. 15, no. 6, pp. 699-700, 2011.

[9] V. Neuhaus, M. Turina, G. Colombo, P. Soklic, and H. P. Simmen, "Intestinal perforation following blunt abdominal trauma in patients with pre-existing inguinal hernia," Der Chirurg, vol. 80, no. 3, pp. 231-237, 2009.

[10] F. Ersoz, S. Arikan, O. Ozcan, and E. Sentatar, "Isolated terminal ileum perforation after a kick blow to an inguinal hernia," Hernia, vol. 13, no. 5, pp. 565-567, 2009.

[11] M. Oncel, N. Kurt, M. Eser, and I. Bahadir, "Small bowel perforation due to blunt trauma directly to the inguinal region: a case report," Hernia, vol. 7, no. 4, pp. 218-219, 2003.

[12] R. N. Uppot, V. K. Gheyi, R. Gupta, and S. W. Gould, "Intestinal perforation from blunt trauma to an inguinal hernia," American Journal of Roentgenology, vol. 174, no. 6, p. 1538, 2000.

[13] P. Nussbaumer, D. Weber, and A. Hollinger, "Traumatic perforation of the small intestine-a rare complication of inguinal hernia," Praxis, vol. 89, no. 21, pp. 934-936, 2000. 
[14] R. D. Reynolds, "Intestinal perforation from trauma to an inguinal hernia," Archives of Family Medicine, vol. 4, no. 11, pp. 972-974, 1995.

[15] K. K. Tan, C. C. Hong, J. Zhang, J. Z. Liu, and R. Sim, "Predictors of outcome following surgery in colonic perforation: an institution's experience over 6 years," Journal of Gastrointestinal Surgery, vol. 15, no. 2, pp. 277-284, 2011.

[16] G. R. Faria, A. B. Almeida, H. Moreira, E. Barbosa, P. Correiada-Silva, and J. Costa-Maia, "Prognostic factors for traumatic bowel injuries: killing time," World Journal of Surgery, vol. 36, no. 4, pp. 807-812, 2012.

[17] O. L. Costa, C. A. Colombo, J. H. Oliveira, M. R. Motta, O. S. Yoshida, and J. Faintuch, "Traumatic injuries of the colon: primary suture or colostomy?," Revista do Hospital das Clinicas, Faculdade de Medicina da Universidade de Sao Paulo, vol. 44, no. 1, pp. 25-28, 1989.

[18] J. Robles-Castillo, A. Murillo-Zolezzi, P. D. Murakami, and J. Silva-Velasco, "Primary repair vs. colostomy in colon injuries," Cirugía y Cirujanos, vol. 77, no. 5, pp. 365-368, 2009.

[19] Y. B. Chol and K. S. Lim, "Therapeutic laparoscopy for abdominal trauma," Surgical Endoscopy, vol. 17, no. 3, pp. 421427, 2003. 


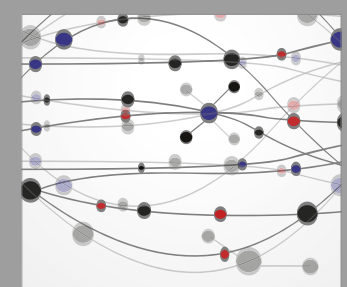

The Scientific World Journal
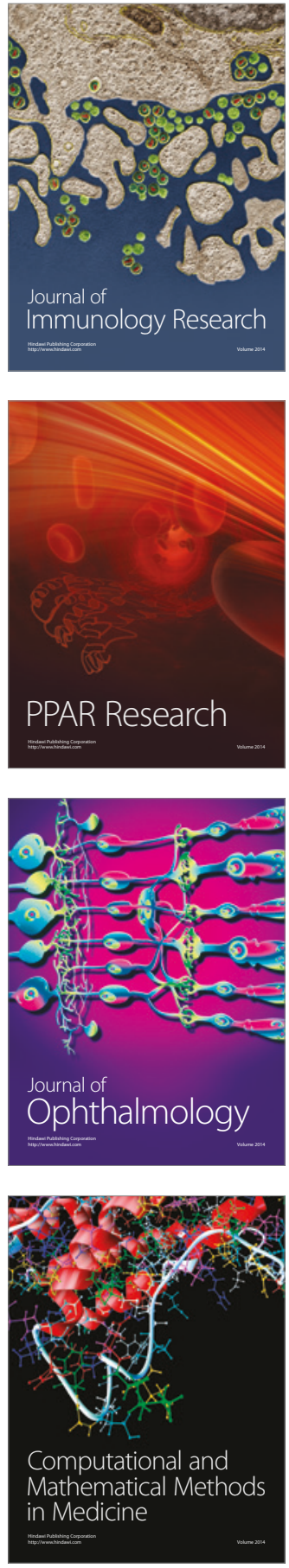

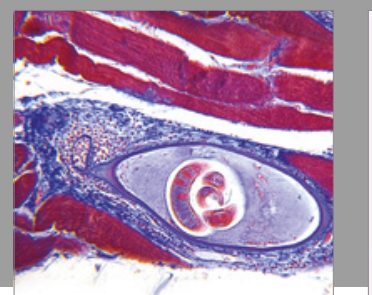

Gastroenterology Research and Practice
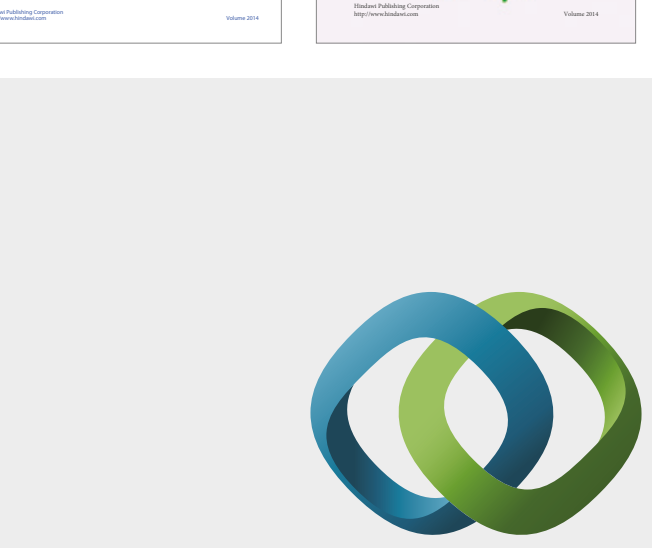

\section{Hindawi}

Submit your manuscripts at

https://www.hindawi.com
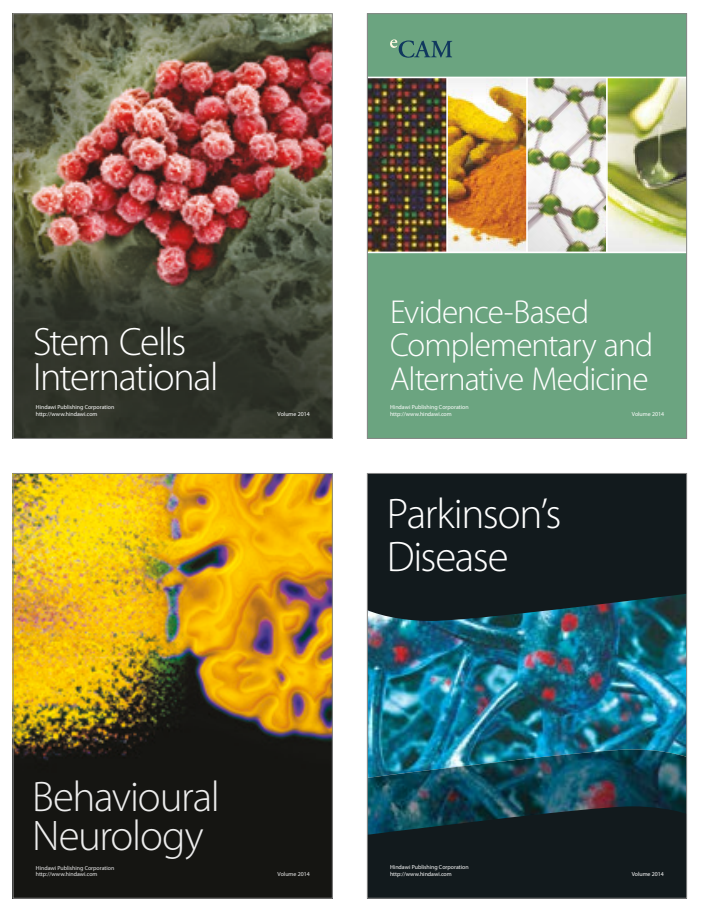
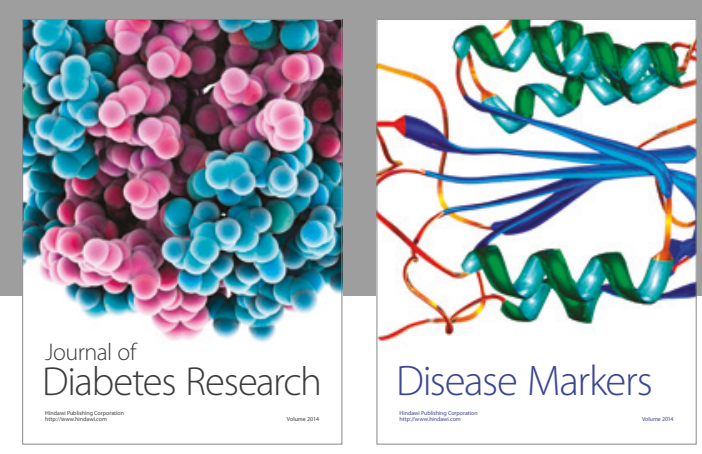

Disease Markers
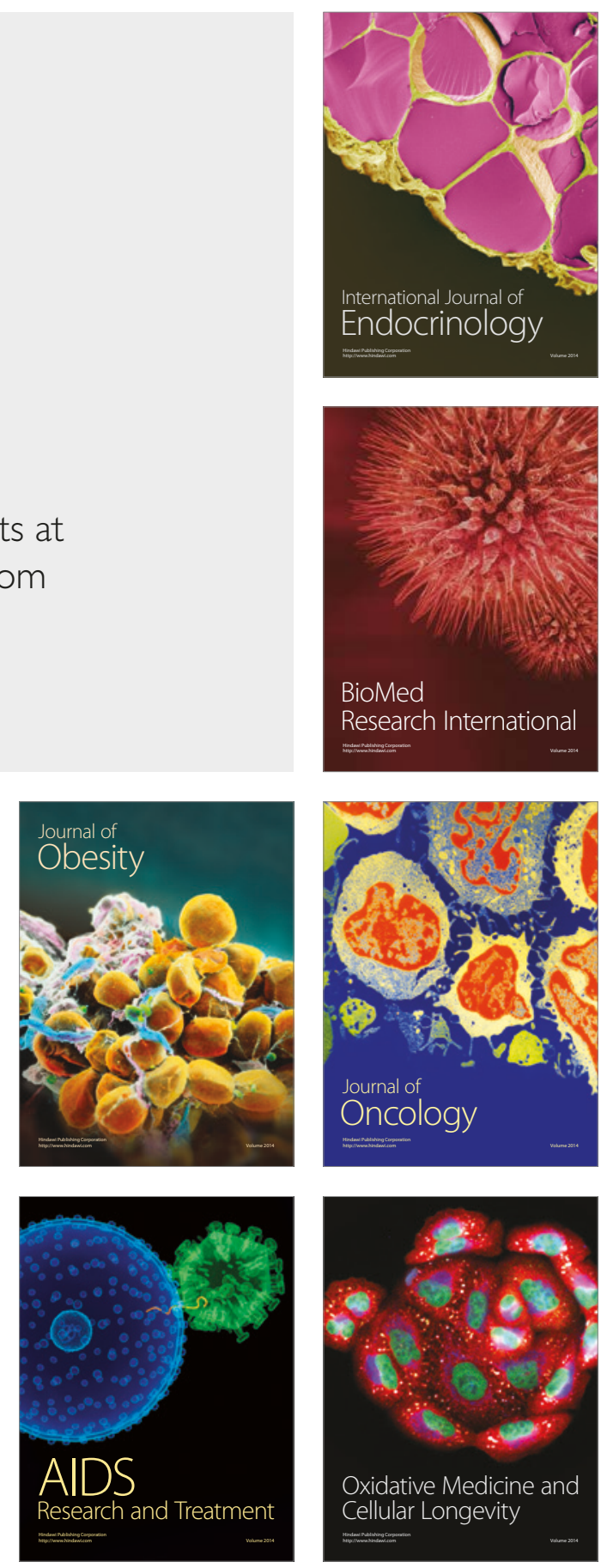